\title{
Iowa's Endangered Cultural Heritage
}

\section{A Personal Essay}

\section{R. Clark Mallam}

$\mathrm{E}_{\text {ACH YEAR more of Iowa's cultural resources disappear. Their }}$ steady depletion, a process not unlike erosion, causes concern and action among preservationists, archaeologists, cultural resource managers, and members of various state and federal agencies. Since the 1950 s their efforts to conserve and to protect the diminishing resource base have resulted in the preservation of many significant prehistoric and historic sites along with a large number of natural areas. Some, however, view preservation, the setting aside of cultural resources through protective means, as the solution to Iowa's escalating resource dilemma. It is not. If destruction of the past is to be averted, preservationists must assume an active role in defining the agents and the causes of destruction and in using them as critical factors in resource planning and the development of a conservation ethic. At this point, there can be little doubt that the primary cause of both cultural and natural resource destruction has been the constant drive for profit in the American society. One of the strongest examples in lowa demonstrating this correlation pertains to the destruction of Native American mounds in the northeastern part of the state.

On April 30, 1892, Theodore H. Lewis arrived at Harpers 
Ferry, Iowa, a small, rural village located along a large terrace overlooking the Mississippi River. At the time he was entering his twelfth year of employment as a surveyor for the Northwestern Archaeological Survey, a monumental project conceived and financed by Alfred J. Hill of St. Paul, Minnesota. Since 1881 Lewis had traveled widely throughout many north central states meticulously carrying out the objectives of the survey program. Hill, fearful that rapidly expanding agricultural and timbering practices would soon destroy many prehistoric mound groups, directed him to record and plat as many of these varying-sized earthen features as possible. During his annual travels, from early spring through late fall, he had become accustomed to daily discoveries of mound groups. Most consisted of rows of conical mounds positioned along ridge crests. Some, however, resembled animals, great bas-reliefs erected in cameo form, while others appeared to be embankments and enclosures. Regardless of their size, number, or duplication, he dutifully recorded them all.

He was unprepared, though, for what he encountered at Harpers Ferry. The terrace did not contain just another repetitious grouping of mounds. Instead, its surface was virtually blanketed with the earthen features-a veritable mosaic of sculpted soil. Quite possibly, this was the largest aggregation of mounds in North America. For nearly a week Lewis remained at Harpers Ferry, daily walking the elongated terrace which extended for almost three miles along the Mississippi River. Undoubtedly, each day's surveys tended to reinforce the preceding day's observations: he had arrived too late. The mounds had been subjected to agriculture for so long - nearly forty years - that their forms were rendered indistinct. All that could be done was to record approximate numbers and forms and to plat those mounds having incurred the least degree of disturbance. On May 4, 1892, he made the following entry in his field notebook:

This group consisted of 107 tailless animals, 67 birds, 98 embankments that were probably animals. 154 embankments and 240 round mounds the largest of which is now about 5 feet high. Total number of effigies in sight including 4 surveyed. 276. Total number of mounds including surveyed. 671 . Add 229 small round 
mounds (estimated) that have been destroyed by cultivation makes a total 900 mounds of all classes. All except about 50 mounds are cultivated. ${ }^{1}$

Thirty-one years later, Charles R. Keyes, director of the Iowa Archaeological Survey, noted only eighteen mounds remaining on the terrace. ${ }^{2}$ This figure was later increased to fifty-two in 1930 when Keyes' colleague in Iowa archaeology, Ellison Orr, undertook a more detailed survey. ${ }^{3}$ Today, less than a dozen can be found, all of which have been disturbed. For all practical purposes, the largest mound group ever recorded in North America may be considered destroyed.

The loss of the Harpers Ferry "Great Group" was not an isolated incident. It was, instead, merely the most spectacular loss, literally one of thousands, in the gradual, consistent erosion of Iowa's prehistoric heritage. How much has been lost may never be known. Data needed for such an assessment do not exist. In the northeastern part of the state, however, research conducted during the past decade indicates just how severe this loss might be and identifies certain factors responsible for the dissolution of the past.

Beginning in the spring of 1973 members of the Luther College Archaeological Research Center developed a research project to study the Effigy Mound culture in Iowa. This prehistoric culture, whose most notable feature is earthen mounds constructed in the forms of animals, had never been studied adequately before. From time to time, various research teams briefly focused attention on it, but no major effort had been initiated to define the mound data base nor to clarify the distribution pattern.

1. Theodore H. Lewis, "Northwestern Archaeological Surveys: Clayton and Allamakee Counties, Iowa," Notebook No. 32, 1892, Minnesota State Historical Society Archives, St. Paul, Minnesota, 15-16.

2. Charles R. Keyes, "The Hill-Lewis Survey," Minnesota History 9 (June 1928):106.

3. Ellison Orr, "Sundry Archaeological Papers and Memoranda," in, Vol. 12: Iowa Archaeological Reports, 1934-1939. Evaluation and index by Marshall McKusick. In Archives of Archaeology. Society for American Archaeology, Microcard Series. Edited by David Baerreis. (Madison: University of Wisconsin Press, 1963). 
Supported by funding from the Iowa State Historical Department's Division of Historic Preservation, project members spent several months engaged in archival research and field surveys. During this time they concentrated on records from the Northwestern Archaeological Survey, 1881 to 1895; the Division of Mound Exploration, Bureau of Ethnology, 1881 to 1890; and the Iowa Archaeological Reports, 1934 to 1939. They recorded notes and plats for known Effigy Mound Groups and then checked their current status through new surveys. During these studies project members also investigated many areas not covered by the previous surveys.

The project's final report tabulated the Effigy Mound groups, the mound classes, their distribution and present status. The study revealed that lowa once possessed at least fifty-three Effigy Mound groups distributed mainly along the bluffs and terraces of the Mississippi River and the lower reaches of its tributaries in northeastern Iowa. These fifty-three groups contained a minimum of 1,426 mounds.

According to prevailing mound terminology, this total was divided into a series of categories with the following frequencies: 374 effigy mounds consisting of nine representative forms, 795 conical, 241 linear and 12 compound mounds, 2 enclosures, and 2 mounds of indeterminate shape. Of these, only 46 effigies and 240 associated mounds could be found in 1973, a depletion rate of over 80 percent. Of fifty-three Effigy Mound groups, only sixteen still could be located and many of those contained mounds which had suffered considerable disturbance. With regard to the effigy forms, thirty were protected by inclusion in federal and state parks but existence of the other sixteen was contingent purely on individual landowner concern. ${ }^{4}$

What factors account for such a staggering loss of materials within a single prehistoric culture? The answer, according to conventional explanations, is relatively simple. Effigy mounds have all but disappeared in Iowa because of the combined effect, through time, of agricultural expansion, industrial growth,

4. R. Clark Mallam, "Report of the Luther College Archaeological Research Center Effigy Mound Survey in Iowa," Iowa State Historical Department, Division of Historic Preservation, Des Moines, Iowa. 
timbering, and vandalism - the "Four Horsemen" of cultural resource management and archaeology.

In reality, the situation is much more complex. The Four Horsemen by themselves do not constitute an explanation for the destruction of effigy mounds or the past in general-they are only agents of a process. This process, indeed, the context, within which the Four Horsemen ride and the destruction of the past occurs is, according to the economist Robert Heilbronner,"-a socioeconomic system built on profit gained from production. . . ." Neither produced goods nor the social values of produced goods are the goal of the system. The goal, clearly and simply, is profit. It permeates, literally penetrates, all facets of the system and structures all relationships between humans and things.

Consequently, it dictates that all things, even the source of life-soil, be translated and transformed into commodities, objects of value. Therefore, when we view the environment we do not see it so much for its intrinsic worth-a web of ecological relationships infused with life-but, rather, for what can be produced from its resources and what individual or corporate profits can be gained therefrom. In other words, the drive for profit and the profit motive form an integral part of the core of the American world view. Together, they substantially influence our behavior and attitudes toward life and the environment.

Economic expression of this world view has resulted in environmental transformation, perhaps the most conspicuous product of the American system. Historically, this evolution from natural ecosystems to social environments has become so extensive that, according to the ecologist Victor Shelford, ninetyeight percent of the original North American ecosystems have been either altered or destroyed. ${ }^{6}$ As Wilbur Jacobs notes in his analysis of Indians as ecologists:

The evidence reveals that Americans and their colonial ancestors altered their natural surroundings and set in motion physical and biological processes that have had reverberating effects on the

5. Robert L. Heilbronner, Marxism: For and Against (New York, 1980), 100.

6. Victor E. Shelford, The Ecology of North America (Urbana, 1963). 
environment. Our environmental past, then, can be viewed as a history of our modification of the earth. ${ }^{7}$

As this historical process has evolved in America, it has unleashed the Four Horsemen, purveyors of destruction who have ridden with few or no restraints. ${ }^{8}$ In their wake they have left a transformed landscape tending toward increasing degrees of biotic impoverishment. Time and again the environment has been assaulted and its resources exploited in order to extract maximum profits with minimum investments. And, the chief product of this profit oriented process has been not so much a list of innumerable consumer commodities but, rather, erosion-physical, social, and spiritual deterioration. It is the antithesis of the Native American perspective regarding human/land relationships. They believed, in contradistinction to the Euro-American view, that humans had to assume responsibility for the quality of life by respecting the environment which enhances it.

In the absence of a land ethic and a sense of resource stewardship, the steady wearing away of the earth through erosion has become a pronounced feature of the American lifeway. The figures annually released by governmental agencies citing loss of soil and prime agricultural land represent little more than a familiar, dreary litany. ${ }^{9}$ We accept loss in our pursuit of profits. Smallwonder, then, that the phrase "acceptable loss" has become a stock term in reference to the environment. It exemplifies both terrestrial erosion and also spiritual erosion, the wearing away of concern.

As the earth wears away, so does the past. In recent years the cultural resource losses have probably reached proportions at least equivalent to those cited for soil. The destruction of the past is directly linked to use of the environment. Whatever is done to the

7. Wilbur D. Jacobs, "Indians as Ecologists and Other Environmental Themes," American Indian Environments, ed. Christopher Vecsey and Robert W. Venables (Syracuse, 1980), 46-64.

8. For an extended discussion of this process, see Peter Wolf, Land in America (New York, 1981).

9. See USDA Soil Conservation Service, "America's Soil and Water: Conditions and Trends" (Washington, D.C., 1980) and Council on Environmental Quality, "The Environment in the Eighties," Environment 23 (July/August 1981):40-45. 
earth is also done to the past. This is what has occurred to the Effigy Mound culture in northeastern Iowa. It has virtually disappeared as agricultural expansion, industrial growth, timbering, and vandalism have transformed a native prairie-forest environment with its earthen monuments into an eroding agricultural and grazing zone. Because mounds had no marketable value in Iowa, or anywhere else for that matter, they were considered to be expendable commodities. Following initial exploration, usually in the form of vandalism masked as archaeology, they were destroyed as the land was modified to correspond to the needs of an expanding profit-motivated, agriindustrial society. Of particular note is the destruction of mound groups along the lower reaches of the Turkey River and the area in and around its confluence with the Mississippi.

T HE TURKEY RIVER is one of five major waterways flowing through northeastern Iowa. Centrally located between the Upper Iowa and Yellow rivers to the north and on the south by the Maquoketa and Wapsipinicon rivers, it is recognized as one of the most archaeologically significant areas of the state. Prior to extensive Euro-American settlement its bluffs and spur ridges contained scores of mound groups. The density of the mound groups increased within the area adjacent to its mouth, principally, the bluffline along the Mississippi River.

The existence of mound groups in this part of Iowa had been known since the earliest period of Euro-American settlement. ${ }^{10}$ Intensive investigation, however, did not occur until the latter quarter of the nineteenth century. At this time, roughly thirty years following statehood, eastern Iowa was being rapidly transformed into a stable, agrarian social environment. The opening of new fields through timber clearing, especially in the uplands of the Turkey River and along the Mississippi bluffs, exposed many mound groups. Their discovery attracted considerable attention and stimulated local interest in the past. In fact, several prominent

10. See E. G. Squier and E. H. Davis, Ancient Monuments of the Mississippi Valley, Smithsonian Contributions to Knowledge, Vol. 1 (Washington, D.C., 1848). 
citizens of Garnavillo elected to carry out excavations in many of them. Ardent believers in the Mound Builder myth, they annually rifled untold numbers of these earthen structures in an effort to obtain data supporting existence of a previous "vanished race."11

Each year Clayton County newspapers enthusiastically reported their investigations and, each year, the mound population steadily decreased as more people became involved in the quest. Preservation does not seem to have been a concern. The land was being transformed and, by nineteenth-century ideological standards, most believed this transformation necessary in order to produce a better and more progressive society. If the mounds were destroyed in this process it was unfortunate; progress exacted a price. Besides, their numbers seemed inexhaustible. As SamuelMurdock, a prominent Clayton County jurist and archaeological enthusiast, noted, his native county alone possessed the remains of at least " 100,000 dead moundbuilders." 12

Meanwhile, the steady advance of timbering and agricultural practices into the uplands and divides caused additional damage to the mound groups. The combined impact of a growing population and poor farming techniques necessitated ever-increasing amounts of cropland. Also, this burgeoning society required enormous amounts of wood for constructing and fueling new homes and businesses. It was a time of growth and prosperity; between 1850 and 1900 Iowa's population expanded from 192,214 to $2,231,853 .{ }^{13}$ It was also a time of erosion. By the turn of the century the climax oak-hickory forests which once covered the uplands and ridges no longer existed; neither did most of the mound groups.

11. Throughout the nineteenth century, many Americans believed that a "vanished race," superior, unrelated, and antecedent to the Native Americans had constructed the earthen mounds. This belief, known historically as the Mound Builder myth, stressed that Native Americans came late to the New World and were responsible for destroying the earlier race of Mound Builders. For a typical account of the myth as it was used to explain local antiquities, see Samuel Murdock, "Prehistoric Races," Iowa Historical Record 4 (January 1888):28-32.

12. Samuel Murdock, "The Mound Builders," Clayton County Journal 1245 (June 1875):1-2.

13. Leland Sage, The History of Iowa (Ames, 1974). 
The only accurate record of mound groups existing in this part of Iowa prior to 1900 was made by Theodore Lewis. Undoubtedly attracted to the Turkey River area by newspaper accounts of the local excavations along with rumors about mounds, he moved into this region on April 15, 1885. For the next two weeks he conducted surveys along the lower portion of the Turkey River and the Mississippi River bluffs adjacent to its mouth. Of the various mound groups he recorded and platted during this time, sixteen may be classified as belonging to the Effigy Mound culture. Together, they contained a total of 101 structures-23 effigy mounds, 25 linear, 46 conical, and 6 compound mounds and 1 enclosure.

Today, ninety-six years later, only three mound groups remain. The remarkable diversity in mound form which characterized the effigies, generally referred to as "panther, turtle, and human," has been almost eradicated. Ironically, their destruction vindicates the extensive labor expended during the course of the Northwestern Archaeological Survey. Had it not been for the foresight of Alfred Hill a substantial amount of the prehistoric information of the Upper Mississippi Valley would have been lost. The existence of Lewis' survey plats and notes, though, in no way mitigates the magnitude of the tragedy. In historical perspective, the destroyed and the present condition of those remaining constitute a cultural resource disaster.

In regard to the remaining mounds, the Turkey River Mound Group, now a state preserve, has lost six of its original twenty-eight mounds and many of those surviving bear the scars of vandalism. The two other effigy mound groups, located two miles away along the bluffs of Adams Mill Hollow have fared much worse. At the time of Lewis' investigations, this deeply enclaved hollow fronting on the Mississippi River floodplain was a veritable garden of mounds. Practically every spur ridge throughout its one mile course contained a mound group. Currently, only two remain and of these the Pete Adams Mound Group \#1 provides the best evidence for assessing the former cultural richness of this area.

According to Lewis, the mound group consisted of one tailed effigy ("panther"?) mound and nine conical and three linear mounds. It was probably much larger. In 1885 part of the ridge on 


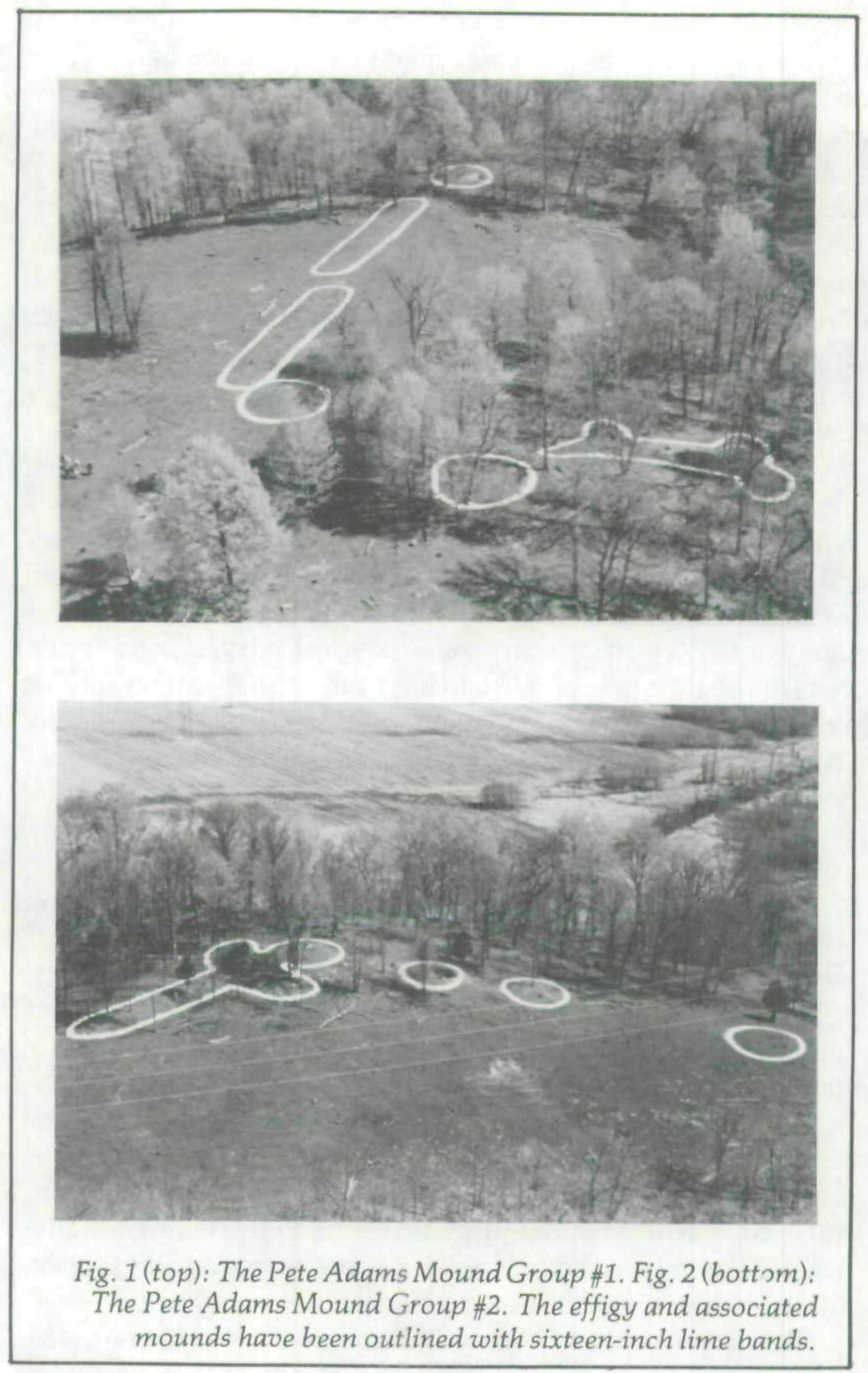


which the mound group is located was already under cultivation. Therefore, it seems likely that the row of conicals he platted might have extended along the ridge for a distance of at least a quarter mile and, possibly, a half mile. (See Fig. 1)

The Pete Adams Mound Group \#2 is located immediately north of this mound group and directly across the hollow. For years it has been well known, largely owing to the unusual form of its single effigy and the three conicals positioned lineally southeast of its "head." (See Fig. 2) Constructed in the form of two irregular crossed linear mounds, it has long been referred to as the "Woman" mound. Apparently, its unusual shape piqued Lewis' curiosity and, uncharacteristically, he opened a "test" pit in the center of the head. He found no artifacts but did recover one skeleton. Continuing on, he virtually leveled the most southern conical, again finding only a skeleton. ${ }^{14}$

These two mound groupssurvived the first transformation of the eastern Iowa environment. Their survival, though, is probably more a function of their remote location than preservation efforts or concern. Regardless, they have not fared well. The "Woman" mound has been plundered several times over since Lewis' arrival by unknown vandals who enlarged his test pit in addition to making some of their own. Based on the presence of scattered limestone blocks and flagstones around its edges this part of the mound might have contained either an interior stone platform or a vault.

By the 1970s the mound sustained additional damage when pigs were turned into the bluff area. In short order they rooted through the potholes magnifying the degree of destruction. After the pigs came the cows. They still graze in this area and, during the afternoons, use the mound and its surrounding trees for a "stand." Over the years their daily trips from the farm below to the bluff have left a labyrinth of eroding paths. After every rain these paths transport flagstones, soil, and the past to the hollow below.

Exacerbating the situation, a power line cuts diagonally across the bluff, blatantly intruding on the integrity of the mound group. To stand under these lines, listening to their paean to

14. Theodore H. Lewis, "Northwestern Archaeological Surveys: Clayton and Allamakee Counties, Iowa," Notebook No. 18, 1885, Minnesota State Historical Society Archives, St. Paul, Minnesota, 5. 
progress, is to experience a sense of spiritual erosion. From this vantage point, the viewer can easily tell that here is an area where the Four Horsemen have ridden freely.

When examined in historical perspective there can be little doubt that erosion has been and is the prime agent in mound destruction. The disappearance of so many of these earthen structures in the Turkey River area since the advent of agriculture strongly supports this correlation. This erosion, however, is not just physical deterioration of the soil; it appears also to be a wasting, a withering of human concern for the environment. In other words, the physical process of erosion possesses a cultural component which manifests itself as the ideology of profit etched into the landscape. The incessant drive for profit celebrated as progress and sanctified through acquisition of material goods and status, has contributed significantly to the removal of the earth's protective blanket and its past.

The disruption of natural vegetation on such a vast scale may be classified as vandalism. How else could one regard human acts which since the 1830s have caused Iowa's forest cover to decline from an estimated seven million acres to less than two million today? Rather than abating, it continues. For example, in response to federal encouragement, Iowans added almost nine million more acres to cultivation during the last decade. Unfortunately, all of it was marginal land. In one year, erosion of these newly cultivated soils resulted in the loss of sixty million tons of soil. ${ }^{15}$

New areas presently being brought under cultivation tend to consist of fields with relatively pronounced gradients. In northeastern Iowa, particularly along the Turkey River, it is not unusual to see ridge slopes converted to cropland. In fact some of the converted land extends nearly to the limestone escarpments. During heavy rains their surfaces erode rapidly leaving behind a dendritic network of ever-widening gullies. As these areas become less productive agriculture moves further out onto the spur ridges.

15. For an expanded treatment of soil loss and erosion see Ken Buckeye, "Cropland Erosion and Farm Economics in the Upper Mississippi Region," Upper Mississippi River Basin Commission River Ramblings 7 (November 1981):7-10; Mildred Grimes, "Top Soil: The Thin Layer of Life," Muses 4 (Summer 1981):3-4; and, George B. Hartman, "The Iowa Sawmill Industry," Iowa Journal of History and Politics 40 (January 1942):52-93. 
Today any ridge wider than two hundred feet is a prime candidate for clearance and conversion.

Clearance usually involves removal of all vegetation with heavy equipment. Denuded and exposed, the thin topsoil erodes within a few years. This loss, though, is really neither an issue nor a concern. Given the form of agribusiness today, the profitmotivated individual no longer needs to search for land with rich soil, only a place where crops may be planted. Their nutritional needs will be met with chemical fertilizers. In effect, the advent of "chemical farming" has led not only to severe alteration of the landscape as marginal lands are brought into production but also to our concept of land. We do not view land as either sacred or a source of life; it is merely a petri-dish, a holding agent for hybridized plants linked to chemical life-support systems. Given this conception, conversion of any area to cropland may be regarded as both practical and profitable because land not used for profit represents wasted land. As the agribusiness economist Susan George states in her evaluation of contemporary farming practices:

Agriculture as practiced in the United States today is hardly "agricultural" at all-it is rather a highly sophisticated, highly energy-intensive system for transforming one series of industrial productsinto another series of industrial products which happen to be edible. ${ }^{16}$

This on-going process of conversion and transformation of natural areas into cropland now invades the last refuge of mounds - the end points of spur ridges and the margins of bluff zones. As these areas become cleared, the mounds disappear along with the vegetation. In fact, clearance proceeds so rapidly and involves so many different areas in northeastern Iowa that it has out-stripped the supervisory capacity of the archaeological community. Moreover, newer techniques and larger equipment facilitate clearing. Projects formerly requiring months to complete can now be accomplished within a few days. A recent technique developed by contractors greatly promotes clearance. It involves use of the mounted fork lift. The prongs of this

16. Susan George, How the Other Half Dies (Montclair, New Jersey, 1977):5. 
instrument are driven horizontally into the base of a mound and then raised vertically, a practice somewhat analogous to paper shredding. It results in removal of brush and the past, both of which constitute obstacles to agricultural production and profit.

Often the soil covering bedrock formations is too thin to permit agriculture. In these instances property owners convert the land to pasture. This process firstentails timbering. After removal of the most productive trees, the land is fenced and opened to grazing. With the admission of cattle, the understory soon disappears, wildlife production declines, the ground surface becomes compacted, and erosion accelerates. If one searches today for those numerous mound groups which Lewis located along the terraces and bluffs of the Mississippi, they will not be found easily. Most have been reduced in height by cattle compaction, many to elevations no greater than one foot. Others are virtually buried by sheet wash resulting from erosion of overgrazed bluff slopes.

\begin{abstract}
As the Four Horsemen-agricultural expansion, industrial growth, timbering and vandalism - ride across Iowa spurred by the drive for profit, they continue to reap an ever-broadening swath of destruction through the state's natural and cultural resources. The intensity of this unrelenting assault causes change in the status of the resources. Once so plentiful that their numbers seemed inexhaustible, they now appear to be seriously endangered. As they steadily decline they become transformed from low-value to high-value commodities. Consequently, this transformation forces archaeologists and naturalists into preservationist positions. There, they seek to secure the remains, "shreds and patches," of past environments and cultures and to incorporate them into preserves, inviolate "islands of sanctity."

Preserves programs, however laudable and well-intentioned, cannot be the sole solution to Iowa's eroding resource dilemma because the structure of preservation contains an inherent contradiction. The major feature of this contradiction
\end{abstract}


centers around the resources. Because they are endangered, various state and federal programs are formed out of concern to promote their protection and management. Unfortunately, these programs become ends in themselves. Once created, usually through legislation, they signify vested interests and in time the resources become critical to maintenance of both the programs and jobs. Therefore, if the programs are to survive, if they are to maintain themselves, they must achieve increasing control over the remaining, declining resources. In essence, the original struggle emanating from concern to protect and to preserve has been transformed into a struggle to protect and to maintain the agents of protection and preservation. The transformed struggle results in agency conflict, power-jockeying, a distinction between and separation of natural and cultural resources, and continuous disputes over access to them. It is magnified further as each agency and program competes and vies against each other for funding and power control at the state and federal levels. These internecine truggles relegate the original concern for the resources to a pusition of secondary importance while concern for the programs becomes preeminent.

In a sense preservation of natural and cultural resources has become a business. Its main concern is to secure greater control over the resources and to use them for the joint purposes of program consolidation and expansion. This is not to say that the programs are ineffective or ill-intentioned. On the contrary they have been responsible for preserving many cultural sites and natural areas. However, while engaged in competition over resource control, funding, and program development these agencies have less and less time and opportunity to define and to analyze the historical factors and conditions which account for the increasing rates of destruction. In their struggle to maintain and to perpetuate themselves they have lost sight of the need to build a single, unified conservation ethic which would bind them together in a program of preservation solidarity.

This conservation ethic already exists. The problem Iowa faces, as do so many other states, is how to recognize and implement it. Historically, the ethic revolves around and emanates from the Native American efforts to establish satisfactory relationships between themselves and the environ- 
ments in which they lived. Quite early, certainly during the Archaic stage in North America ( 8000 B.C. to 1500 B.C.), they recognized that humans would always live in disharmony with the natural world. This tenuous state of existence was caused by human exploitation of the natural world. If humans were to survive they had to exploit nature and exploitation caused nature to suffer.

They never resolved this contradiction. By recognizing it for what it was, however, they were able to deal with the tension it produced. Essentially, they saw the natural world as the ultimate source of life. It was part of them, they were part of it. The natural web of life formed the basis for social life, a special relationship that would always exist between humans and the natural world. Without using the source of life, without taking life, though, humans could not live. Therefore, their response to this contradiction, to its tension producing features, was the creation of an ethic manifest as a social contract: humans must assume responsibility for the quality of life by respecting the environment which enhances it. It required humans to treat members of the natural world as relatives and, more so, to treat them with respect, sensitivity, and reverence. The taking of life by humans, then, necessitated an act of contrition, an apology to the spirit of the animal or plant and to the source of life which gave birth to both the hunter and the hunted. This act of requesting forgiveness constituted the central feature of the ethic. It required humans to be ever-mindful that they were part of life, not distinct from it. ${ }^{17}$

Americans have never acknowledged the plausibility of this ethic. They cannot because it is diametrically antithetical to the expansionistic needs of a system whose very existence is predicated on increasing profits. As long as profits and acquisition of material goods continue to be our personal and national goals,

17. For in-depth analyses of Native American environmental beliefs, see Christopher Vecsey, "American Indian Environmental Religions," in American Indian Environments, 1-37; Dennis Tedlock and Barbara Tedlock, eds., Teachings from the American Earth (New York, 1975); Sam D. Gill, Native American Religions (Belmont, California, 1982); Gary Witherspoon, Language and Art in the Navajo Universe (Ann Arbor, 1977); and Ake Hultkrantz, The Religions of the American Indians (Berkeley, 1967). 
the ethic will be ignored and the Four Horsemen will ride unimpeded, destroying indiscriminately more and more natural and cultural resources.

Is there a solution to this dilemma? Perhaps. Presently, many people desire a new land use bill, one which legislates conservation by providing an intricate system of incentives, rewards, and punishments for those who participate in its central objective of judicious use of resources. Close analysis reveals, though, that this kind of legislation is not innovative. It is merely the same interest in profit cloaked in a different form. It attempts to make preservation and conservation profitable. In the long run, it may slow the process of destruction caused by profit-motivated behavior but the long term impact on resources probably will remain the same.

Alternately, the land use bill may be seen as a beginning in our search for more constructive means to conserve and to interact with the source of life. The fact that such a bill currently is being considered indicates that we are slowly, ever so slowy, coming to the realization that something more than chemicals must be put into the soil each spring. That "something" has not yet been well defined nor articulated. But, most important, it denotes an uneasiness about our present relationship to the environment and a growing awareness that perhaps what must be planted along with the seed is concern. To implant this kind of concept would be tantamount to practicing the Native American act of contrition. If we are to ask forgiveness from the source of life for our actions, if we are to secure its blessing, its cooperation, we then must offer in return our most prized possession-profit. This is the lesson of the past-one receives from the environment only by participating in its maintenance. It may be the meaning of the effigy mounds.

We must stress to the young that the goal of life is not profit but quality. This belief-must be incorporated into our world view to the extent that it is sowed in the minds of each succeeding generation. Weneed to affirm, to them and to ourselves, through a newly forged social contract, this most basic cosmological conviction borne out of the Native American experience. If this could be achieved preservation and conservation would no longer be issues; they would be instead part of our social, economic, and spiritual behavior. To use the past in this way, as a model, is to 
recognize where we have been, where we are, and the possibilities for transforming ourselves and our social environment. What we can learn from the past and how its lessons might be used has been summarized provocatively by the historian Frederick Turner in his analysis of Native American and Euro-American values:

Standing for this, they can also speak to us of what should have been the American Dream: that of spiritual regeneration here in these vast, untamed lands, through learning to value differences, accepting our own limitations as well as those of others, and by marrying ourselves to an environment we have yet to learn to live with. ${ }^{18}$

18. Frederick Turner, "The Terror of the Wilderness," American Heritage 28 (February 1977):65. 
Copyright of Annals of Iowa is the property of State of Iowa, by \& through the State Historical Society of Iowa and its content may not be copied or emailed to multiple sites or posted to a listserv without the copyright holder's express written permission. However, users may print, download, or email articles for individual use. 